\title{
Symptoms and longitudinal changes in lung function in young seasonal grain handlers
}

\author{
A L JAMES, WOCM COOKSON, G BUTERS, S LEWIS, G RYAN, R HOCKEY, \\ A W MUSK
}

From the Department of Respiratory Medicine, Sir Charles Gairdner Hospital, Nedlands, Western Australia 6009

\begin{abstract}
A total of 119 seasonal grain handlers (mean age 23) were assessed before and towards the end (mean work period 18 days) of the 1983 Western Australian grain harvest to determine if respiratory symptoms that occur with exposure to grain dust are associated with changes in ventilatory capacity or non-specific bronchial reactivity to methacholine. Eighteen per cent of subjects had wheeze, breathlessness, or chest tightness and $18 \%$ had cough or sputum production at work. Subjects complaining of wheeze, chest tightness, or breathlessness at work had a significantly greater decline in $\mathrm{FEV}_{1}$ than subjects who did not experience these symptoms $(p<0.05)$. Symptoms were not associated with changes in bronchial reactivity. In young grain handlers who develop respiratory symptoms on short term exposure to grain dust changes in $\mathrm{FEV}_{1}$ but not in non-specific bronchial reactivity have been demonstrated.
\end{abstract}

Exposure to dusts of wheat, oats, and barley at work is commonly associated with wheeze, breathlessness, cough and sputum, and airflow obstruction in both smokers and non-smokers. ${ }^{1-5}$ Factors associated with the development of grain related respiratory effects in previous investigations include cigarette smoking, ${ }^{67}$ increased bronchial reactivity, ${ }^{8}$ and atopy. ${ }^{39}$ In these previous studies most workers had had many years of exposure to grain dust and probably represented survivor populations, workers with troublesome symptoms having resigned. In one previous study of subjects with little or no previous occupational exposure to grain a history of wheeze, the presence of increased non-specific bronchial reactivity, and positive skin tests to fungal allergens were related to the development of respiratory symptoms occurring with exposure to grain dust at work. ${ }^{10}$ In the present study a similar group of seasonal workers was examined before and after a period of work at grain storage sites to determine if those subjects who experienced work related respiratory symptoms also developed changes in respiratory function (including bronchial reactivity) or skin test responses to grain or other common allergens.

\section{Subjects}

In Western Australia the transport, storage, and marketing of grain is carried out by a single, government administered cooperative. Each year temporary workers are hired as grain samplers, weighbridge officers, and general hands at grain receival and storage sites. About a third of these are employed from outside the wheat growing district, at the central Perth office: 143 consecutive subjects were included in the study when applying at the Perth office for work in the north western region of the wheat growing district. They represented $34 \%$ of all seasonal workers employed from this office. They were currently unemployed or students working during their summer vacation. Thirteen of the applicants included in the preseason assessment were not subsequently employed and were excluded from further study. Of the remaining 130 subjects, $119(92 \%)$ were available for follow up at the end of the season. Nine were retrenched or resigned for non-medical reasons during the season, one refused to participate further, and one left his job because of a gastrointestinal illness. There were no differences in the preseason characteristics between subjects who were not employed or who left work and the subjects who were available for follow up. 


\section{Methods}

Preseason assessment was carried out at the time of application for work. The British Medical Research Council questionnaire on respiratory symptoms (1976) was administered regarding history of cough and sputum, breathlessness, wheeze, chest tightness, sneeze or itchy nose, and history of asthma, hayfever, eczema, or allergy. A smoking history was recorded and additional questions regarding occupational history and previous exposure to grain dust were also included.

Prick skin tests were performed using extracts of the following groups of commercially available allergens; "common" (cat and dog dander, house dust, house dust mite), "grain" (whole grain wheat, rye, oats, barley, wheat pollen, wheat mite), "fungi" (aspergillus mix, alternaria, penicillium, cladosporium), and 'grasses' (canary grass, perennial rye grass, wild oats, and bermuda grass)(Hollister-Stier, Elkhart, USA). A weal of $3 \mathrm{~mm}$ or more greater than the negative control was considered a positive reaction. If one or more prick skin test to any allergen was positive the subject was considered to be atopic. Subjects were further categorised as being positive to grass, grain, or fungi according to their having positive skin test responses to allergens in each of these groups.

Forced expiratory volume in one second $\left(\mathrm{FEV}_{1}\right)$ and forced vital capacity (FVC) were measured using a wedge spirometer (Vitalograph, Buckingham, England). Three forced expiratory manoeuvres which were within $5 \%$ of the best FVC were recorded. ${ }^{11}$ From these the best FEV 1 and FVC were measured and corrected to BTPS. ${ }^{12}$

Bronchial reactivity was measured using the method of Yan et al ${ }^{13}$ to a maximum cumulative inhaled dose of methacholine of $120 \mu$ moles. Bronchial reactivity was expressed as the provocative dose of methacholine required to produce a $20 \%$ fall in $\mathrm{FEV}_{1}$ from the postsaline control value (PD20).

Subjects were reassessed toward the end of the harvest season at their workplaces. A second intervieweradministered questionnaire concerning duration of employment, the nature of their jobs, and work related symptoms (cough, sputum, shortness of breath, wheezing, chest tightness, difficulty breathing, sneezing, or itchy nose or eyes) was completed. They were also asked, "Did work with grain affect your chest?" Skin tests were repeated using the same batch of allergen extracts as at first assesssment and $F_{E V}$, FVC, and bronchial reactivity were remeasured. Bronchial reactivity was categorised as having increased or decreased during the season if the PD20 changed by more than one doubling concentration. ${ }^{14}$ The same technicians performed the measurements at both assessments. Two spirometers were used for measurements and were calibrated directly agains each other and with a three litre syringe.

\section{Results}

A total of 102 men and 17 women completed the study; their mean age was 23 (range 18-63) and 52\% were smokers. Fifty per cent had had previous exposure to grain dust as seasonal grain handlers? although no subject had handled grain within the paș 10 months. There were no significant differences in symptoms, skin test responses, ventilatory capacit $\xi_{\omega}^{\omega}$ or bronchial reactivity at the beginning or at the end of the harvest season between subjects with history of exposure to grain and those without. Fifty one peis cent of subjects were atopic and $62 \%$ had a PD20 of less than $120 \mu$ moles of methacholine (table 1). Cougb and sputum, before and after the work period, were related to cigarette smoking $(p<0.05)$. As in the pree vious study ${ }^{10}$ the presence of preseason atopy and $a$. positive prick skin test to grain antigen were associss ated with a history of asthma, wheeze, or hay fevero $(p<0.05)$. Preseason bronchial reactivity was greate in subjects with atopy $(p<0.01)$ and a history of asthma $(\mathrm{p}<0.05)$.

Eighteen per cent of subjects experienced wgrt related lower respiratory tract symptoms (breân lessness, wheeze, chest tightness, or cough and ș. tum) and $72 \%$ experienced work related upper piratory symptoms (sneeze and itchy nose or eyes (table 2). The development of wheeze, breathlessness or chest tightness at work was associated with a hisp tory of wheeze $(p<0.001)$ or asthma $(p<0.002)$

Table 1 Preseason characteristics in 119 subjects

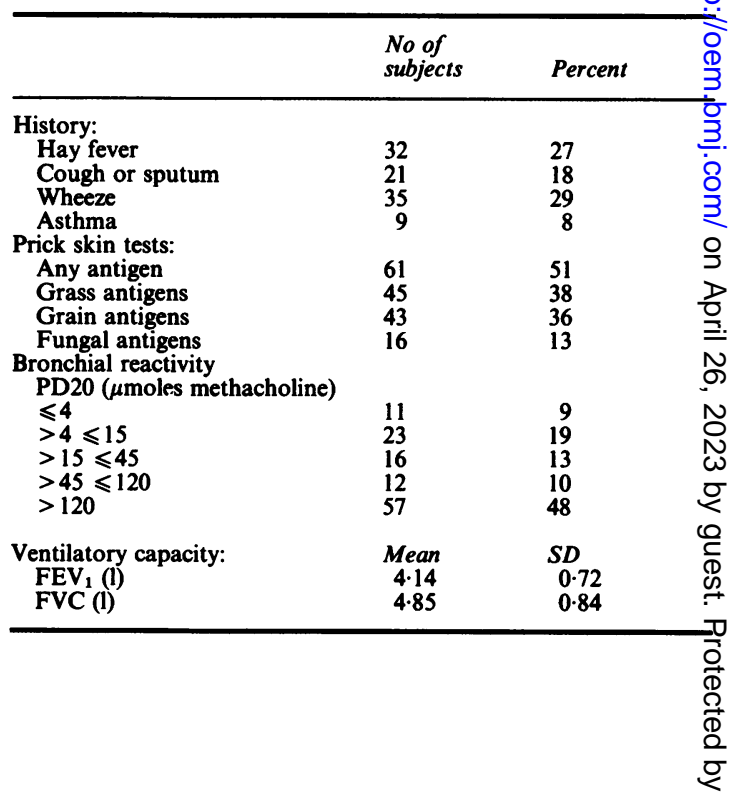


Table 2 Incidence of work related symptoms over the work period in 119 seasonal grain handlers

\section{No of}

subjects Per cent

Symptoms at work:

Upper respiratory tract Any

Sneeze

Itchy eyes or nose

Cough and sputum

Lower respiratory tract

Any

Breathlessness

Wheeze

Chest tightness

$\begin{array}{rr}97 & 82 \\ 79 & 66 \\ 44 & 37 \\ 21 & 18 \\ 22 & 18 \\ 8 & 6 \\ 15 & 13 \\ 11 & 9\end{array}$

These symptoms were also associated with atopy (p $<0.05)$ as in the previous study. ${ }^{10}$ In the present study, however, the preseason level of bronchial reactivity was not related to the subsequent development of symptoms at work. Work related upper respiratory symptoms were associated with a history of hay fever $(\mathrm{p}<0.01)$. Symptoms at work were not related to the particular job that was performed during the season or to changes in skin test responses between the beginning and the end of the season.

During the course of the season $\mathrm{FEV}_{1}$ fell by 0.0741 (SD 0.021 1, p < 0.001) in all subjects. The fall in $\mathrm{FEV}_{1}$ was significantly associated with work related breathlessness (table 3) and was greater in those who considered that work with grain had affected their chests. The fall in $\mathrm{FEV}_{1}$ during the course of the season was not related to skin test responses to any group of allergens either before or after the season or to preseason PD20 or the fall in PD20 over the work period. Changes in $\mathrm{FEV}_{1}$ and FVC were not related to preseason atopy or bronchial reactivity, type of job, previous grain exposure, or smoking.

Wheeze, breathlessness, or chest tightness occurred in $37 \%(7 / 19)$ of subjects whose bronchial reactivity increased during the season, $8 \%(1 / 13)$ in those with no change, and in $24 \%(8 / 33)$ of those whose bronchial reactivity decreased over the season. These differences were not significant.

\section{Discussion}

This study has shown that subjects who complained of breathlessness when exposed to grain dust at work experienced a significant decrease in $\mathrm{FEV}_{1}$ during the season. It extends the previous work which showed that respiratory symptoms at work in a similar group of seasonal grain handlers were frequent and were related to a history of wheeze, asthma, or hay fever, an increased level of bronchial reactivity, and positive prick skin test responses to a variety of allergens ${ }^{10}$ by showing that of these symptoms breathlessness at work is associated with a significant decline in $\mathrm{FEV}_{1}$ during the course of the season. Thus it indicates that adverse respiratory effects may be measured after short periods of exposure in subjects with little or no previous exposure to grain dust.

A separate (unexposed) control group was not included in this study because subjects lacking a characteristic of interest acted as the "control" or "comparison" group for those with the particular characteristic.

We attempted to study subjects without previous

Table 3 Decrease in FEV 1 between preseason and follow up assessment, work related symptoms, prick skin test responses, and bronchial reactivity

\begin{tabular}{|c|c|c|}
\hline \multirow[b]{2}{*}{ Symptoms at work } & \multicolumn{2}{|l|}{ Characteristic } \\
\hline & Present & Absent \\
\hline $\begin{array}{l}\text { Present: } \\
\text { Shortness of breath** } \\
\text { Chest tightness } \\
\text { Wheeze } \\
\text { Shortness of breath or chest } \\
\text { tightness or wheeze* } \\
\text { Sneeze or itchy eyes or nose } \\
\text { Prick skin test positive: } \\
\text { Preseason (any) } \\
\text { End season (any) } \\
\text { Preseason bronchial reactivity: } \\
\text { PD20 < } 4 \mu \mathrm{mol} \\
\text { PD20 < } 15 \mu \mathrm{mol} \\
\text { PD20 < } 120 \mu \mathrm{mol} \\
\text { Increase in bronchial reactivity } \\
\text { during the season } \\
\text { "Did work with grain affect } \\
\text { your chest?"* }\end{array}$ & $\begin{array}{l}0.263 \pm 0.120(8) \\
0.023 \pm 0.071(14) \\
0.167 \pm 0.073(15) \\
0.177 \pm 0.055(22) \\
0.067 \pm 0.024(97) \\
0.073 \pm 0.037(61) \\
0.102 \pm 0.030(69) \\
0.050 \pm 0.078(14) \\
0.078 \pm 0.044(37) \\
0.084 \pm 0.034(65) \\
0.094 \pm 0.062(28) \\
0.191 \pm 0.080(14)\end{array}$ & $\begin{array}{l}0.060 \pm 0.021(112) \\
0.061 \pm 0.021(101) \\
0.061 \pm 0.022(105) \\
0.051 \pm 0.023(98) \\
0.102 \pm 0.050(23) \\
0.075 \pm 0.021(59) \\
0.036 \pm 0.030(51) \\
0.077 \pm 0.022(106) \\
0.072 \pm 0.024(83) \\
0.062 \pm 0.025(55) \\
0.068 \pm 0.021(92) \\
0.054 \pm 0.021(105)\end{array}$ \\
\hline
\end{tabular}

Mean values \pm SD (number of subjects).

Significance of difference in decrease of $\mathrm{FEV}_{1}$ between subjects with characteristic present and absent ${ }^{*} p<0.05,{ }^{* *} p<0.02$. 
James, Cookson, Buters, Lewis, Ryan, Hockey, Musk $\frac{\text { m }}{\bar{c}}$

exposure to grain dust to overcome the problem of selection bias when studying a population of long term workers. There was no evidence that selection had already occurred to a significant degree since the prevalence of atopy, history of asthma or wheeze, and the level of bronchial reactivity in this study was similar in those subjects with and those without previous occupational exposure to grain dust and similar to that in the general Australian population. ${ }^{1516}$

In the present study neither the preseason level of bronchial reactivity nor the change in bronchial reactivity with exposure to grain were related to the occurrence of symptoms at work or change in $\mathrm{FEV}_{1}$ with grain exposure. In prevalence studies in the grain industry others have shown that symptomatic grain handlers have increased non-specific bronchial reactivity, ${ }^{1718}$ but it is not clear whether the increased bronchial reactivity is present before, or develops after, exposure to grain dust. Unlike the present study, that of Cookson et al suggested that, in addition to atopy, the prior level of bronchial reactivity is important in determining symptoms on exposure. ${ }^{10}$ Possibly longer periods of exposure or higher levels of airborne grain dust, or both, occurring in the previous study account for the differences between the two studies.

The frequency of respiratory symptoms and changes in lung function are related to levels of grain dust exposure in long term grain handlers. ${ }^{19}$ Grain dust levels were not measured in this study because the nature of the work dictated that exposure was usually intermittent, brief, and intense, mostly being performed out of doors. Thus the frequency of symptoms in the subjects appeared lower than that seen in grain elevator workers elsewhere ${ }^{\mathbf{3}}$ but similar to other groups of grain workers employed out of doors. ${ }^{19} 20$ Whereas the highest exposures to grain dust in our group were experienced inside storage bins or while unloading grain trucks, few of the subjects were concerned in these activities and we were unable to find a difference in frequency of symptoms and lung function between different job categories. A knowledge of the levels and the patterns of exposure to the various constituents of grain dust may further our understanding of the changes we have documented.

Other studies have examined the effects of grain in populations of older, long term grain handlers who were probably exposed to higher levels of dust and who had longer histories of smoking. ${ }^{1-61920}$ These groups have a reduced prevalence of atopy compared with non-exposed populations, suggesting that selective exclusion of atopic subjects has occurred. ${ }^{8}$ This finding is compatible with the results of this and the previous study ${ }^{10}$ in which atopic subjects experienced more adverse respiratory symptoms, which may dis-

future.

This study has shown that grain workers who: develop breathlessness at work have a measurable decrease in $\mathrm{FEV}_{1}$ during the course of a harvest season. Measurements of lung function were made only before and after a period of exposure to graip dust and were not coupled to direct measurements of grain dust levels. More frequent measurements of ventilatory capacity, bronchial reactivity, and duse? constituents and levels are needed to examine theip inter-relations and also to determine if recovery of lung function occurs after cessation of exposure.

The help of the management and staff of $\mathrm{Co}$ operative Bulk Handling of Western Australia and Elizabeth Bingle is gratefully acknowledged.

Request for reprints to: Dr AW Musk.

\section{References}

1 Williams NO, Skoulas A, Merriman JE. Exposure to grain dust A survey of health effects. J Occup Med 1964;6:319-29.

2 Sheridan D, Deutscher C, Tan L, et al. The relationship between exposure to cereal grain dust and pulmonary function in $8 \mathrm{f}$ workers. In: Dosman JA, Cotton DJ, eds. Occupationator monary disease: focus on grain dust and health. New Academic Press, 1980:229-38.

3 do Pico GA, Reddan W, Flaherty D, et al. Respiratory aḅnto malities among grain handlers: a clinical, physiologic, an immunologic study. Am Rev Respir Dis 1977;115:915-27.

4 Chan-Yeung M, Schulzer M, MacLean L, Dorken E, Gryz bowski S. Epidemiological health survey of grain elevat $\mathrm{A}$ workers in British Columbia. Am Rev Respir D 1980;121:329-38.

5 Dosman JA, Cotton DJ, Graham BL, Froh F, Barnett GD Chronic bronchitis and decreased forced expiratory flow rates in lifetime nonsmoking grain handlers. Am Rev Respir $\bar{D}$ 1980;121:11-6.

6 Cotton DJ, Graham BL, Li KYR, Froh F, Barnett GD, Dosma JA. Effects of grain dust exposure and smoking on respirato symptoms and lung function. J Occup Med 1983;25:131-41. O

7 Chan-Yeung M, Wong R, MacLean L. Respiratory abnormalis. ties among grain elevator workers. Chest 1979;75:461-7.

8 Gerrard JW, Mink J, Sze-Shuen CC, Cheung C, Tan LKDosman JA. Nonsmoking grain handlers in Saskatchewant airways reactivity and allergic status. $J$ Occup Me? 1979;21:342-6.

9 Skoulas J, Williams N, Merriman JE. Exposure to grain dust if A clinical study of the effects. J Occup Med 1964;6:359-62.

10 Cookson WOC, Ryan G, MacDonald S, Musk AW. Atopy, noriv allergic bronchial reactivity, and past history as determinans of work-related symptoms in seasonal grain handlers. $\mathrm{Br} J \mathrm{InAP}$ Med 1986;43:396-400.

11 American Thoracic Society. Statement-Snowbird workshop ofp standardisation of spirometry. Am Rev Respir Dis 1979;119 831-8.

12 Cotes JE. Lung function. 3rd ed. Oxford: Blackwell Scientific Publications, 1975:20.

13 Yan K, Salome C, Woolcock AJ. Rapid method for measurement of bronchial responsiveness. Thorax 1983;38:760-5.

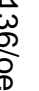


14 Ryan G, Dolovich MB, Roberts RS, et al. Standardisation of inhalation provocation tests: two techniques of aerosol generation and inhalation compared. Am Rev Respir Dis 1981;123: 195-9.

15 Britton W, Sedgwick C, Woolcock AJ. Prevalence of allergy and asthma in Australian children. Aust NZ J Med (in press).

16 Woolcock AJ, Yan K, Stuckey M. Bronchial responsiveness in an adult population. Proceedings of the annual scientific meeting of the Thoracic Society of Australia, May 1983. Aust NZ J Med 1983;13:542.

17 Broder I, Davies G, Hutcheon M, et al. Variables of pulmonary allergy and inflammation in grain elevator workers. $J$ Occup
Med 1983;25:43-7.

18 Mink JT, Gerrard JW, Cockcroft DW, Cotton DJ, Dosman JA. Increased bronchial reactivity to inhaled histamine in nonsmoking grain workers with normal lung function. Chest 1980;77:28-31.

19 Corey P, Hutcheon M, Broder I, Mintz S. Grain elevator workers show work-related pulmonary function changes and doseeffect relationships with dust exposure. $\mathrm{Br} J$ Ind Med 1982;39:330-7.

20 Warren CP, Manfreda J. Respiratory symptoms in Manitoba farmers: association with grain and hay handling. Can Med Assoc J 1980;122:1259-64.

\section{Vancouver style}

All manuscripts submitted to the $B r J$ Ind Med should conform to the uniform requirements for manuscripts submitted to biomedical journals (known as the Vancouver style).

The $B r J$ Ind Med, together with many other international biomedical journals, has agreed to accept articles prepared in accordance with the Vancouver style. The style (described in full in $\mathrm{Br}$ Med J, 24 February 1979, p 532) is intended to standardise requirements for authors.

References should be numbered consecutively in the order in which they are first mentioned in the text by Arabic numerals above the line on each occasion the reference is cited (Manson' confirmed other reports ${ }^{2-5} \ldots$.). In future references to papers submitted to the $\mathrm{Br} J$ Ind Med should include: the names of all authors if there are six or less or, if there are more, the first three followed by $e t$ al; the title of journal articles or book chapters; the titles of journals abbreviated according to the style of Index Medicus; and the first and final page numbers of the article or chapter.

Examples of common forms of references are:

' International Steering Committee of Medical Editors. Uniform requirements for manuscripts submitted to biomedical journals. Br Med J 1979; 1:532-5.

2 Soter NA, Wasserman SI, Austen KF. Cold urticaria: release into the circulation of histamine and eosinophil chemotactic factor of anaphylaxis during cold challenge. $N$ Engl $J$ Med 1976;294:687-90.

${ }^{3}$ Weinstein L, Swartz MN. Pathogenic properties of invading micro-organisms. In: Sodeman WA Jr, Sodeman WA, eds. Pathologic physiology: mechanisms of disease. Philadelphia: W B Saunders, 1974:457-72. 